\title{
ANTIULCEROGENIC EFFICACY OF ETHANOLIC EXTRACT OF VITIS VINIFERA LEAVES IN RATS
}

\author{
DAWLAT A. SAYED, SOHAIR R. FAHMY, AMEL M. SOLIMAN, NAGAT S. HUSSEIN \\ Zoology Department, Faculty of Science, Cairo University, Egypt \\ Email: dawlat82@gmail.com
}

Received: 14 May 2016 Revised and Accepted: 22 Jul 2016

\begin{abstract}
Objective: The ethanolic extract of Vitis vinifera leaves (VVE) $(500 \mathrm{mg} / \mathrm{kg}$ body weight), ranitidine $(50 \mathrm{mg} / \mathrm{kg}$ body weight) and both of them were tested for their gastroprotective and curative effects against the incidence of peptic ulcer.

Methods: The antiulcer effects of VVE were investigated using a combination of indomethacin and cold-stress for $2 \mathrm{~h}$. To ascertain the mechanism of action of VVE, its protective and curative effects were studied on gastric volume, gastric juice acidity, ulcer index and malondialdehyde (MDA), glutathione (GSH), catalase (CAT), glutathione-S-transferase (GST), superoxide dismutase (SOD), nitric oxide (NO) activities of both stomach and duodenum of rats. Moreover, histopathological effects on stomach and duodenum were determined.

Results: The antioxidant activity of VVE was demonstrated using 2, 2-diphenyl-1-picrylhydrazyl (DPPH) test. VVE was found to reduce the ulcer index, gastric volume and the level of gastric juice acidity. Also, VVE showed gastroprotective and curative activities mainly through improvement of antioxidant status and decreasing lipid peroxidation accompanied with amelioration of both stomach and duodenum architectures.
\end{abstract}

Conclusion: The prophylactic and curative effects of VVE proved to be effective in preventing gastric and duodenal ulceration which may be probably due to its antioxidant and anti-acid secretory effects.

Keywords: Severe gastric ulcer, Rats, Indomethacin, Cold stress, Oxidative stress

(C) 2016 The Authors. Published by Innovare Academic Sciences Pvt Ltd. This is an open access article under the CC BY license (http://creativecommons. org/licenses/by/4. 0/) DOI: http://dx.doi.org/10.22159/ijpps.2016v8i9.12846

\section{INTRODUCTION}

Peptic ulcer represents the most common cause of upper gastrointestinal (GI) bleeding [1]. The stomach can resist to a large variety of noxious factors, which depend on a number of physiological responses elicited by the mucosal lining against potentially harmful luminal agents [2]. Gastric ulcers affect many people around the world, and their development is a result of the imbalance between the offensive and defensive factors [3]. The offensive factors include gastric acid back-diffusion and oxyradical generation leading to an interruption in the mucosal integrity [4]. While defensive factors involves GSH and mucus biosynthesis $[5,6]$.

The major detrimental effects on gastric mucosa are exerted by nonsteroidal anti-inflammatory drugs (NSAIDs), the most prescribed group of drugs in the world [7]. These drugs are able not only to exert gastric injuring effects but also to delay the healing of ulcer lesions through a variety of local and systemic mechanisms [8]. These effects are mainly mediated through inhibition of prostaglandin synthesis [9].

Indomethacin is widely used to treat inflammatory diseases and manage pain, fever and inflammation in several conditions, including gastric ulcer [10]. Indomethacin-induced gastric ulcer by inhibition of prostaglandins which are cytoprotective to gastric mucosa [11]. Moreover, it was reported that indomethacin causes significant gastrointestinal damage [12] and several enteropathic consequences, including oxidative stress [13].

Cold resistant stress (CRS) induced gastric ulcer as a result of autodigestion of the gastric mucosal barrier, accumulation of $\mathrm{HCl}$ and generation of free radicals $[14,15]$. Oxidative stress is caused by an imbalance between a biological system's ability to readily detoxify the reactive intermediates and the production of reactive oxygen species (ROS) [16]. The generation of these ROS plays a major role in the development of multiple pathologies, such as gastritis, peptic ulcerations or gastric adenocarcinoma [17].

Gastric ulcer remains a serious health problem in the worlds, and the available therapeutic regimens are directed towards the enhancement of defensive mechanism and reduction of the aggressive factors [18].

The goal of treating ulcer disease is to relieve pain, heal the ulcer and prevent its' recurrence [19]. Ranitidine (RAN) is a synthetic antiulcer drug that blocks acid secretion. Treatment with RAN has an ability to antagonize the binding of histamine to the $\mathrm{H}_{2}$-receptor on the parietal cells. Therefore, it can counter the effect of indomethacin on acid secretion $[20,21]$. Since the clinical evaluation of synthetic drugs has shown the incidence of some adverse effects, treatment with natural products is now considered as an alternative approach for the treatment of gastric ulcer. Plants are some of the most attractive sources of new drugs, and some have been shown to have promise for the treatment of gastroduodenal ulcer with minimum side effects $[22,23]$.

Grapes, belong to the family Vitacea, are one of the richest sources of polyphenols among fruits $[24,25]$. They are very potent natural antioxidants due to its phytochemical constituents such as phenolic acids, flavonols, stilbenes (Resveratrol), anthocyanins and proanthocyanidins [26-28]. VVE contains mostly myricetin, ellagic acid, kaempferol and quercetin [29]. In addition, VVE contains Gallic acid that has been shown to possess various therapeutic properties, including antioxidant, anti-cancer, anti-inflammatory and antiviral activities $[30,31]$.

So, the present study aims to assess the protective and curative effects of the VVE in comparison with RAN in a model of indomethacin-cold stress induced gastric ulcer in male albino rats to elicit the underlying in vivo antioxidative mechanisms.

\section{MATERIALS AND METHODS}

\section{Experimental animals}

Male albino Wister rats (Rattus norvegicus) weighing 180-200 g were purchased from the animal house of National Research Center, Cairo, Egypt. The animals were housed in polypropylene cages (five animals per cage) for $72 \mathrm{~h}$ before the commencement of the experiments for acclimatization, at controlled conditions of 
temperature $18{ }^{\circ} \mathrm{C}$ with a $12 \mathrm{~h}$ light: $12 \mathrm{~h}$ dark cycle. Rats were fed standard diet and tap water ad libitum.

\section{Ethical consideration}

Experimental protocols and procedures used in this study were approved by the Cairo University, Faculty of Science Institutional Animal Care and Use Committee (IACUC) (Egypt), (CUFS/PHY/ $02 / 15$ ). All the experimental procedures were carried out in accordance with international guidelines for care and use of laboratory animals.

\section{Drugs and chemicals}

Indomethacin was obtained from Sigma Chemical Co. (St. Louis, MO. USA), 2, 2-diphenyl-1-picrylhydrazyl (DPPH), Ranitidine (RAN) (50 $\mathrm{mg} / \mathrm{kg}$ )-(Zantac ${ }^{\mathrm{T} M}$ ) was obtained from EL-Ezaby Pharmacy (Dokki St, Egypt). The kits for all biochemical parameters and other chemicals and reagents were purchased from the Biodiagnostic Company (El Motor St, Dokki, Egypt).

\section{Collection, identification and authentication of plant}

Grape leaves (Vitis vinifera L.) were purchased from a local market in Egypt.5 Kilograms of Vitis vinifera were locally collected in the month of April, 2015. The plant material was authenticated in Botany Department, Faculty of Science, Cairo University, Egypt on the basis of taxonomic characters and by direct comparison with the herbarium specimens that available at the herbarium of the Botany Department. The healthy leaves of VVE were collected and washed with tap water.

After cutting the leaves into small pieces, they were air-dried at room temperature for $14 \mathrm{~d}$ and then the dried leaves were crushed into a fine powder by blender machine. The powder ( $50 \mathrm{~g})$ was mixed with $450 \mathrm{ml}$ of alcohol $(70 \%)$ for $72 \mathrm{~h}$ at room temperature and stirred four times daily. The mixture was filtered with Whatman filter paper (No.1) and then the solvent was evaporated at room temperature. The obtained extract powder was $7.8 \mathrm{~g}(16 \%$ extraction ratio) which stored at $4{ }^{\circ} \mathrm{C}$ until being used.

\section{Determination of antioxidant activity (free radical scavenging activity)}

The 2,2-diphenyl-1-picrylhydrazyl (DPPH) free radical scavenging assay was carried out for the evaluation of the antioxidant activity. This assay measures the free radical scavenging capacity of the investigated extract. DPPH is a molecule containing a stable free radical in the presence of an antioxidant,which can donate an electron to DPPH, the purple color typical for free DPPH radical decays and the absorbance change is measured at $517 \mathrm{~nm}$. The method was carried out as described by [32]. The following concentrations of VVE and vitamin C (standard antioxidant) concentrations were prepared $10,20,30,40,50,60,70$, and 80 $\mathrm{mg} / \mathrm{ml}$ in each tube. $2 \mathrm{ml}$ of DPPH; $(250 \mathrm{~mm} \mathrm{DPPH} / 200 \mathrm{ml}$ methanol) then added the certain concentration of each extract, and adjust the final volume to be $4 \mathrm{ml}$ with methanol. The solution was shaken and incubated at $37 \mathrm{C}$ for $30 \mathrm{~min}$. Methanol was used as a blank and DPPH only was used as a control. The decrease in absorbance (Abs) was measured at $\kappa=517 \mathrm{~nm}$. The radical scavenging activity was calculated from the following equation:

$$
\text { Radical scavenging activity }=[\text { Abs (control)-Abs (sample) } / \text { Abs }
$$$$
\text { (control)] X100 }
$$

\section{Preliminary phytochemical screening}

Preliminary phytochemical screening was carried out using an appropriate solvent extract of the leaves to identify the presence of different active constituents using the procedures [33-36].

\section{Toxicity study (OECD 420)}

Acute toxicity was calculated as OECD guidelines 420 (Fixed dose method) [37, 38]. Ten male Wistar albino rats weighing (180-200 g) were used for acute toxicity study. The animals were divided into control and test groups (5 rats/group). The rats of the test group were administered orally with VVE of $5000 \mathrm{mg} / \mathrm{kg}$ body weight. Normal control rats received the same amount of vehicle (distilled water) only. Animals were observed carefully for $24 \mathrm{~h}$ after extract administration and then for the next $14 \mathrm{~d}$. At the end of this experimental period, the rats were observed for signs of toxicity, morphological behavior, and mortality. Acute toxicity was evaluated based on the number of deaths (if any).

\section{Induction of severe gastric ulcers (SGU)}

The ulcer was induced by a combination of indomethacin and cold stress [39]. Indomethacin was administered as the single oral dose $(150 \mathrm{mg} / \mathrm{kg})$ [40] dissolved in $5 \%$ sodium bicarbonate [41], and the rats were kept in cold stress for $2 \mathrm{~h}$ at a temperature of $3-5^{\circ} \mathrm{C}$ [42].

\section{Experimental protocol}

Before the experiment, rats were deprived of food, but not water, for 20-24 h. The animals (40 rats) were randomly assigned into four main groups:

1. The control group (5 rats/group): Rats administered distilled water orally.

2. Ulcer group (5 rats/group): The rats were exposed to severe gastric ulcer (SGU) model.

3. Prophylactic group (15 rats/group): Rats of this group were assigned randomly into three subgroups (5 rats/subgroup) as follows:

Rats of the $1^{\text {st }}$ subgroup were received single oral dose of VVE $(500$ $\mathrm{mg} / \mathrm{kg}$ ), rats of the second subgroup were administered RAN (50 $\mathrm{mg} / \mathrm{kg}$ ) and rats of the $3^{\text {rd }}$ subgroup were treated with both $V V E$ and RAN. After one hour of all treatments, rats challenged for SGU model for $2 \mathrm{~h}$ then all rats were sacrificed.

4. Curative group: (15 rats/group): Rats of this group were assigned randomly into three subgroups (5 rats/subgroup). After $2 \mathrm{~h}$ of ulcer induction, rats were received single oral dose of VVE or RAN or their combination. After one hour of the treatments, all rats were sacrificed.

\section{Animals handling}

At the end of the experimental period, animals were euthanized after being fasted overnight under deep anesthesia with sodium pentobarbital. Stomach and duodenum were removed and immediately blotted using filter paper to remove traces of blood; then the stomach was dissected out, incised along the greater curvature and the gastric juice was collected. Mucosa was rinsed with cold normal saline to remove blood contaminant. The hemorrhagic and ulcerative lesions of the stomach were counted, then the stomach and duodenum of rats stored at $-80{ }^{\circ} \mathrm{C}$ for biochemical analysis.

\section{Macroscopic evaluation of stomach}

The stomach ulcerative lesions were determined according to Parmar and Desai [43] and Kulkarni [44]. The numbers of ulcers were counted. Scoring of ulcer will be made as follows:

$0.0=$ normal colored stomach,

$0.5=$ red coloration,

$1.0=$ spot ulcers,

$1.5=$ hemorrhagic streaks,

$2.0=$ ulcers with area $>3$ but $\leq 5 \mathrm{~mm}^{2}$,

$3.0=$ ulcers $>5 \mathrm{~mm}^{2}$,

Ulcer index $(\mathrm{UI})=\mathrm{UN}+\mathrm{US}+\mathrm{UP} \times 10$

Where UI = ulcer index, $\mathrm{UN}=$ average number of ulcers per animal, US = average of severity score and UP = percentage of animals with ulcer.

The percentage of inhibition (\%) was calculated by the following formula:

$\%$ inhibition $=100-[$ UI treated $] /[$ UI control $] \times 100$ 


\section{Analysis of gastric juice}

\section{Determination of gastric volume}

Gastric juice collected from each animal was centrifuged at 1000 rpm for $10 \mathrm{~min}$ to remove any solid debris and the volume of the supernatant was measured.

\section{Determination of gastric acidity}

An aliquot of $1 \mathrm{ml}$ of gastric juice diluted with $1 \mathrm{ml}$ distilled water was taken in a conical flask and titrated against $0.01 \mathrm{~N} \mathrm{NaOH}$ with phenolphthalein as an indicator till a permanent pink color is obtained [45]. The volume of $\mathrm{NaOH}$ was then noted. The total acidity, expressed as $\mathrm{mEq} / \mathrm{l}$ was then calculated using the following formula:

$$
\text { Acidity }=\frac{\text { Volume of } \mathrm{NaOH} \times \text { Normality } \times 100 \mathrm{mEq} / \mathrm{l}}{0.1}
$$

\section{Tissue homogenate preparation}

Stomach and duodenum tissues were homogenized $(10 \% \mathrm{w} / \mathrm{v})$ in ice cold $0.1 \mathrm{M}$ phosphate buffer $(\mathrm{pH} 7.4)$. The homogenates were centrifuged at $3000 \mathrm{rpm}$ for $15 \mathrm{~min}$ and the supernatants were used for the estimation of oxidative stress markers.

\section{Determination of oxidative stress markers}

Oxidative stress markers were detected in the resultant supernatant of stomach and duodenum homogenate. The appropriate kits Biodiagnostic Dokki, Giza, Egypt) were used for the determination of malondialdehyde (MDA) [46], glutathione reduced (GSH) [47], nitric oxide (NO) was determined according to [48]. Catalase (CAT) was detected according to the method described by [49] glutathione-STransferase (GST) [50] and superoxide dismutase (SOD) [51].

\section{Histopathological studies}

The stomach and duodenum from each group were fixed in $10 \%$ formalin for $24 \mathrm{~h}$. The specimens were then embedded in paraffin, sectioned and stained with hematoxylin and eosin, before being evaluated by light microscopy.

\section{Statistical analysis}

The data obtained from acute toxicity studies were analyzed using Student's t-test. P values less than 0.05 were considered significant. All results were expressed as mean \pm standard error (SE) of five animals in each group. All data obtained were analyzed by ANOVA followed by Duncan's test. Values of $\mathrm{P}<0.05$ were considered as statistically significant. All computations were performed using SPSS version 20.0 software.

\section{RESULTS}

\section{Free radical scavenging activity}

The results of DPPH scavenging activity of VVE and ascorbic acid were shown in fig. 1 . The radical scavenging activity was estimated by comparing the percentage of DPPH radical inhibition of the tested extract and the ascorbic acid. The present results showed that VVE produced dose-dependent inhibition of DPPH radical ranging from $96.4 \%$ to $109.3 \%$ as compared to vitamin C.

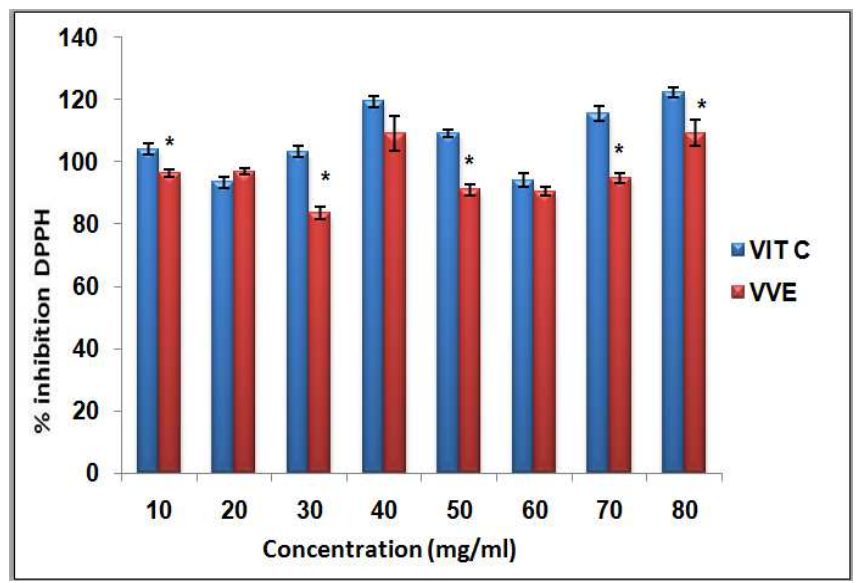

Fig. 1: Antioxidant activity of Vitisvinifera leaves extract (VVE) and vitamin C (Vit. C). Each vertical column represents the mean \pm SEM of change of 3 samples

*: Significantly different as compared to Vit. C.

Table 1: Preliminary photochemical screening of Vitisvinifera leaves extract

\begin{tabular}{ll}
\hline Phytochemicals test & Test \\
\hline Test for glycosides & + \\
Test for flavonoids & + \\
Test for sterols & + \\
Test for saponins & + \\
Test for resin & + \\
Test for alkaloids & - \\
Test for Quinines & - \\
Test for tannins & + \\
\hline
\end{tabular}

\footnotetext{
+: Presence of the constituents, -: Absence of the constituents
}

\section{Phytochemical screening}

The preliminary phytochemical screening carried out on VVE revealed the presence of Phytoconstituents such as glycoside, flavonoids, sterols, saponins, terpenoids, tannins, phenolic acids and resin (table 1).

\section{Acute toxicity study}

Single oral administration of $5000 \mathrm{mg} / \mathrm{kg}$ body weight of $V$. vinifera leaves extract did not show any visible signs of toxicity, abnormal behaviors, or mortality, which indicated that the median lethal dose $\left(L_{50}\right)$ of the tested extract was higher than $5000 \mathrm{mg} / \mathrm{kg}$ body 
weight. All animals survived for $14 \mathrm{~d}$. The effective dose (ED50) of $V V E(500 \mathrm{mg} / \mathrm{kg})$ was selected based on this proposed $\mathrm{LD}_{50}$.

\section{Antiulcer effects of Vitis vinifera leaves extract (VVE) on gastric lesions}

Administration of indomethacin (150 mg/kg body weight) and coldrestraint stress caused a severe gastric ulcer (SGU) covering the entire glandular area of the stomach (fig. 2B). In SGU linear hemorrhagic lesions were seen as red streak lesions. Pre or posttreatment with VVE and/or RAN showed the significant healing effect of the gastric lesions (fig. 2C-H).

However, oral pre-treatment with VVE, RAN and VVE+RAN significantly reduced the ulcer index, showing $82.36 \%, 88.05 \%$ and $87.55 \%$ ulcer inhibition, respectively (table 2 ). In addition, oral posttreatment with VVE, RAN and VVE+RAN reduced the ulcer index significantly, recorded $87.64 \%, 77.56 \%$ and $73.61 \%$ ulcer inhibition, respectively (table 2).

\section{Effect of VVE on gastric volume and gastric acidity}

As shown in table (2), administration of indomethacin at a dosage of $150 \mathrm{mg} / \mathrm{kg}$ body weight and cold stress caused a significant increase in the gastric volume in the gastric lumen, as compared to the normal control group.

However, treatment with VVE, RAN and VVE+RAN either pre or post SGU induction significantly $(\mathrm{p}<0.05)$ decreased the gastric volume (table 2). In addition, the level of gastric juice acidity was significantly $(\mathrm{p}<0.05)$ decreased from $164.4 \mathrm{mEq} / \mathrm{l}$ in the SGU group to $56.6,28.0$ and $84.2 \mathrm{mEq} / \mathrm{l}$ in the pre-treatment VVE, RAN and VVE+RAN groups, respectively (table 2). Whereas, post-treatment with VVE, RAN and VVE+RAN induced a significant $(\mathrm{p}<0.05)$ decrease in the gastric juice acidity, recording 28.0, 28.4 and38.0 $\mathrm{mEq} / \mathrm{l}$, respectively (table 2 ).

Evaluation of oxidative stress biomarkers in gastric and duodenal mucosal tissues

Table 3 shows that the level of gastric malondialdehyde (MDA) increased significantly $(\mathrm{P}<0.05)$ subsequent to $\mathrm{SGU}$, as compared to the corresponding control group. However, the administration of VVE, RAN and VVE+RAN either pre or post-treatment decreased significantly $(\mathrm{P}<0.05)$ the levels of MDA in both stomach and duodenum, as compared to the corresponding SGU group (table 3 and fig. 3A).

Results recorded in table 3and4 and Fig. 3B, C and E showed that SGU induction significantly decreased $(\mathrm{P}<0.05) \mathrm{GSH}, \mathrm{GST}$ and SOD levels, as compared to the control rats in both stomach and duodenum. Pre or post-treatment with VVE, RAN and VVE+RAN significantly increased $(\mathrm{P}<0.05)$ the gastric and duodenal GSH, GST and SOD levels, as compared to the corresponding SGU group.

Statistical analysis revealed a significant increase $(\mathrm{P}<0.05)$ in CAT activities in gastric and duodenal tissue after indomethacin administration and cold stress, as compared to the control group (table 4 and fig. 3 D). Pre or post-treatment with VVE, RAN and VVE+RAN significantly decreased $(\mathrm{P}<0.05)$ CAT activity as compared to the SGU group in both stomach and duodenum (table 4 and fig. $3 \mathrm{D}$ ).

SGU significantly decreased $(\mathrm{P}<0.05)$ NO level of the stomach and duodenum, as compared to the control rats (table 3 and fig. $3 \mathrm{~F}$ ). Pre and post-treatments are induced significant increase $(\mathrm{P}<0.05)$ in gastric and duodenal mucosal NO activity as compared to SGU group.

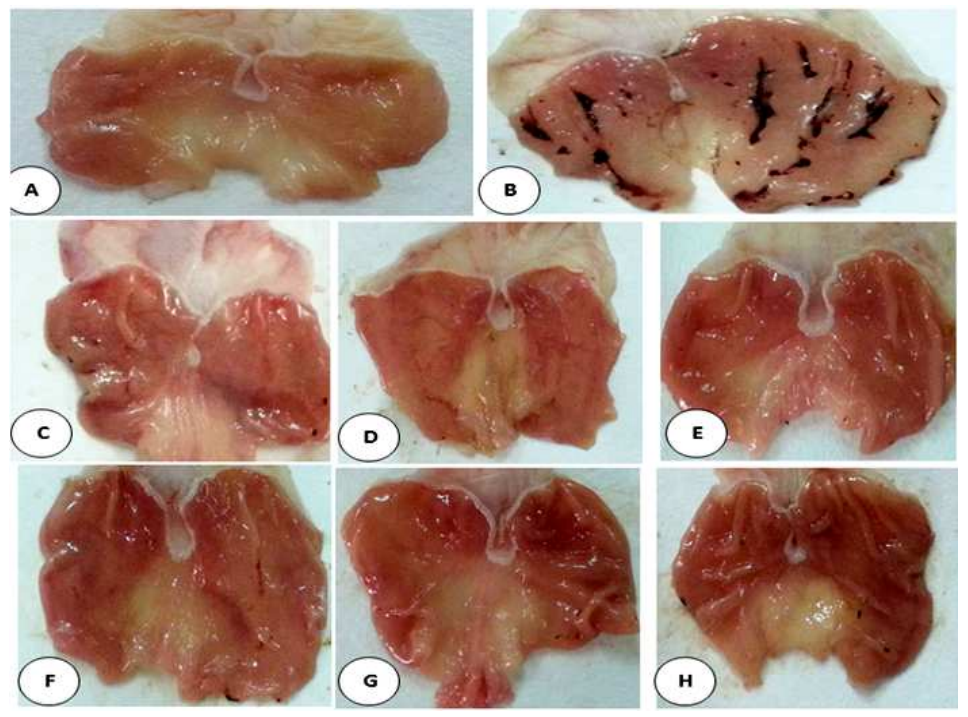

Fig. 2: Macroscopic analysis of rat's stomach. Stomach of control group is showing normal morphological appearance (A). Administration of indomethacin with cold stress resulted in a severe gastric mucosal injury (B). Pre-treated groups: VVE (C), RAN (D), VVE+RAN (E), Posttreated groups: VVE (F), RAN (G) and VVE+RAN (H), showing improvement as compared to ulcer group (B)

Table 2: Antiulcer effects of vitis vinifera leaves extract (VVE) and/or ranitidine (RAN) on gastric ulcer inhibition, gastric juice volume, and total gastric acidity in indomethacin and cold stress-induced gastric ulcer (SGU) in rats

\begin{tabular}{|c|c|c|c|c|c|}
\hline & & Gastric ulcer index & $\begin{array}{l}\text { Gastric ulcer } \\
\text { Inhibition (\%) }\end{array}$ & $\begin{array}{l}\text { Gastric juice } \\
\text { volume (ml) }\end{array}$ & $\begin{array}{l}\text { Total gastric } \\
\text { acidity }(\mathrm{mEq} / \mathrm{l})\end{array}$ \\
\hline & Control & 0 & - & $2.54 \pm 0.24^{\mathrm{abc}}$ & $25.6 \pm 3.59^{a}$ \\
\hline & SGU & $0 \mathrm{e} 360 \pm$ & - & $3.96 \pm 0.13^{d}$ & $164.4 \pm 17.6^{c}$ \\
\hline \multirow{3}{*}{ Pre treatment } & VVE & $63.50 \pm 1.46^{b}$ & 82.36 & $1.70 \pm 0.67 \mathrm{ab}$ & $56.6 \pm 7.9^{a b}$ \\
\hline & RAN & $43.0 \pm 1.46^{\mathrm{a}}$ & 88.05 & $1.54 \pm 0.22^{\mathrm{a}}$ & $28.0 \pm 4.05^{\mathrm{ab}}$ \\
\hline & VVE+RAN & $44.80 \pm 1.68^{\mathrm{a}}$ & 87.55 & $3.40 \pm 0.21^{\mathrm{cd}}$ & $84.2 \pm 4.51^{\mathrm{b}}$ \\
\hline \multirow[t]{3}{*}{ Post treatment } & VVE & $44.50 \pm 1.50^{\mathrm{a}}$ & 87.64 & $1.96 \pm 0.20^{\mathrm{ab}}$ & $28.0 \pm 17.2^{\mathrm{ab}}$ \\
\hline & RAN & $81.16 \pm 1.07 \mathrm{c}$ & 77.56 & $2.20 \pm 0.36^{\mathrm{abc}}$ & $28.4 \pm 4.20^{\mathrm{ab}}$ \\
\hline & VVE+RAN & $95.0 \pm 1.50^{\mathrm{d}}$ & 73.61 & $2.28 \pm 0.40^{\mathrm{abc}}$ & $38.0 \pm 10.6^{\mathrm{ab}}$ \\
\hline
\end{tabular}

Values are given as mean \pm SE for 5 rats in each group. Values with different superscript letters are significantly different $(\mathrm{P}<0.05)$. 
Table 3: Effect of Vitis vinifera (VVE) extract on some oxidative stress markers in gastric tissue in indomethacin and cold stress induced gastric ulcer (SGU) in rats

\begin{tabular}{|c|c|c|c|c|}
\hline & Group & $\begin{array}{l}\text { MDA } \\
\text { (nmol/g tissue) }\end{array}$ & $\begin{array}{l}\text { GSH } \\
\text { (mg/g tissue) }\end{array}$ & $\begin{array}{l}\text { NO } \\
(\mu \mathrm{mol} / \mathrm{l} / \mathrm{mg} \text { tissue })\end{array}$ \\
\hline & Control & $2.17 \pm 0.2^{\mathrm{a}}$ & $77.4 \pm 5.88^{c}$ & $17.71 \pm 1.13^{\mathrm{d}}$ \\
\hline & SGU & $8.45 \pm 1.42^{c}$ & $47.0 \pm 2.84^{\mathrm{a}}$ & $10.13 \pm 1.01^{\mathrm{a}}$ \\
\hline \multirow{3}{*}{ Pre treatment } & VVE & $2.72 \pm 0.51^{\mathrm{ab}}$ & $63.5 \pm 4.35^{b}$ & $11.71 \pm 0.87 \mathrm{abc}$ \\
\hline & RAN & $2.77 \pm 0.3^{\mathrm{ab}}$ & $62.9 \pm 4.130^{\mathrm{b}}$ & $14.65 \pm 1.04^{c}$ \\
\hline & VVE+RAN & $3.60 \pm 0.36^{\mathrm{ab}}$ & $56.80 \pm 3.38^{\mathrm{ab}}$ & $12.58 \pm 0.87 \mathrm{abc}$ \\
\hline \multirow[t]{3}{*}{ Post treatment } & VVE & $3.38 \pm 0.21^{\mathrm{ab}}$ & $57.7 \pm 2.8^{\mathrm{ab}}$ & $11.07 \pm 0.70^{\mathrm{ab}}$ \\
\hline & RAN & $3.17 \pm 0.45^{\mathrm{ab}}$ & $62.2 \pm 6.60^{\mathrm{b}}$ & $11.71 \pm 0.55^{\mathrm{abc}}$ \\
\hline & VVE+RAN & $4.57 \pm 0.57^{b}$ & $65.8 \pm 4.75^{b c}$ & $13.99 \pm 1.38^{\mathrm{bc}}$ \\
\hline
\end{tabular}

Values are given as mean $\pm \mathrm{SE}$ for 5 rats in each group. Values with different superscript letters are significantly different $(\mathrm{P}<0.05)$.

Table 4: Effect of Vitis vinifera leaves extract (VVE) on some oxidative stress enzymes in gastric tissue in indomethacin and cold stress induced gastric ulcer (SGU) in rats

\begin{tabular}{|c|c|c|c|c|}
\hline & Group & GST (u/g tissue) & Catalase (u/mg tissue) & SOD (u/g tissue) \\
\hline & Control & $1.249 \pm 0.13^{c}$ & $277.8 \pm 37.98^{\mathrm{a}}$ & $16.62 \pm 1.16^{\mathrm{c}}$ \\
\hline & SGU & $0.478 \pm 0.068^{a}$ & $856.9 \pm 89.4^{\mathrm{d}}$ & $7.11 \pm 0.41^{\mathrm{a}}$ \\
\hline \multirow[t]{3}{*}{ Pre treatment } & VVE & $0.867 \pm 0.14^{b}$ & $566.25 \pm 61.88^{c}$ & $8.92 \pm 1.22^{b}$ \\
\hline & RAN & $0.599 \pm 0.07 \mathrm{ab}$ & $407.5 \pm 66.39 \mathrm{abc}$ & $7.61 \pm 1.19^{b}$ \\
\hline & VVE+RAN & $0.796 \pm 0.09 \mathrm{~b}$ & $567.9 \pm 19.72^{c}$ & $7.75 \pm 0.40^{\mathrm{b}}$ \\
\hline \multirow[t]{3}{*}{ Post treatment } & VVE & $0.680 \pm 0.04^{\mathrm{ab}}$ & $372.3 \pm 60.97 \mathrm{ab}$ & $8.11 \pm 1.19^{b}$ \\
\hline & RAN & $0.648 \pm 0.07^{a}$ & $516.4 \pm 31.59 \mathrm{bc}$ & $10.3 \pm 1.70^{\mathrm{b}}$ \\
\hline & VVE+RAN & $0.781 \pm 0.04^{b}$ & $334.4 \pm 21.61^{\mathrm{a}}$ & $8.07 \pm 0.66^{b}$ \\
\hline
\end{tabular}

Values are given as mean \pm SE for 5 rats in each group. Values with different superscript letters are significantly different $(\mathrm{P}<0.05)$.
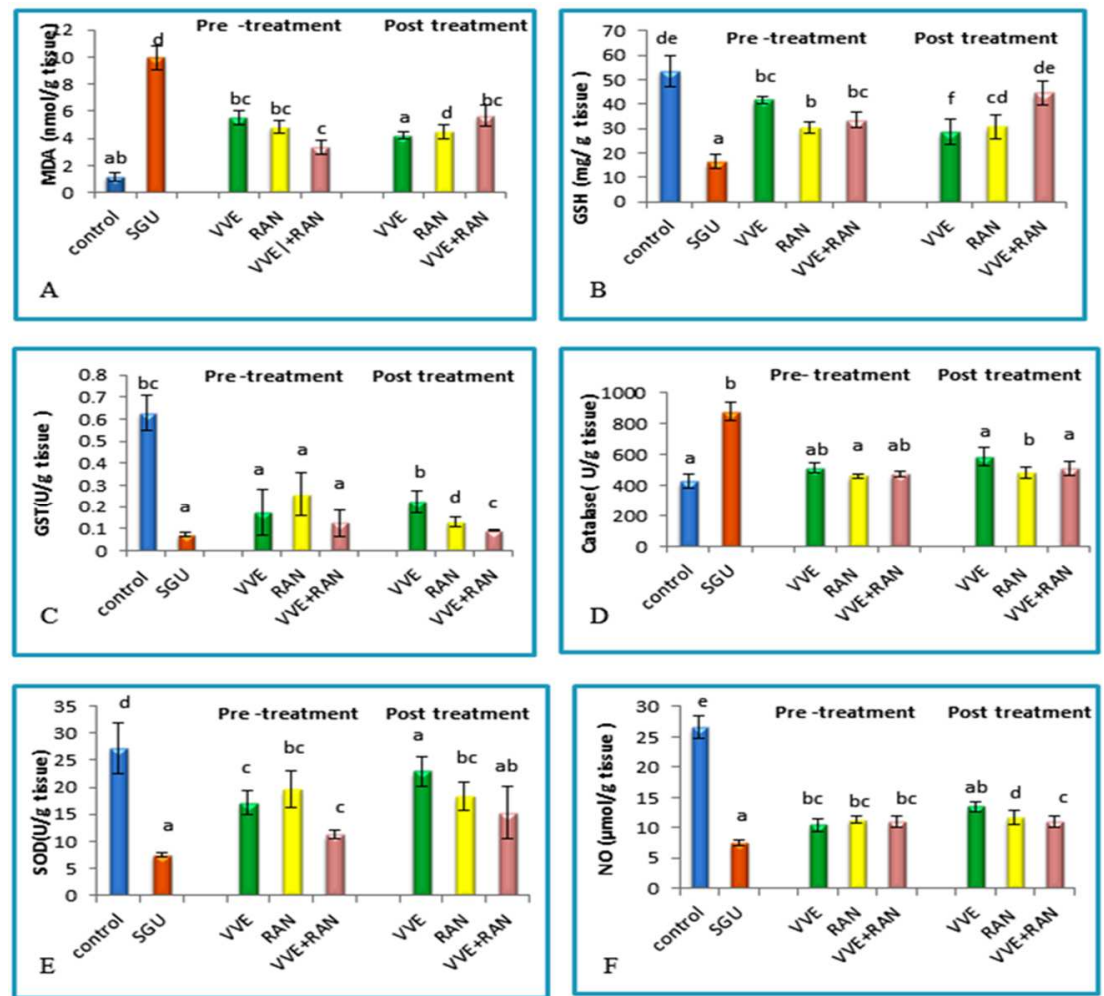

Fig. 3: Effect of Vitis vinifera leaves extract (VVE) on some oxidative stress markers in duodenal tissue in indomethacin and cold stress induced duodenal ulcer (SGU) in rats

Values are given as mean \pm SE for 5 rats in each group. Values with different superscript letters are significantly different

\section{Histological evaluation of gastric and duodenal lesions}

Stomach section of rats from the control group (fig. 4A) showed normal gastric mucosa, where the mucosa is intact, no infiltration of cells, any edema was seen, and normal crypt structure with normal submucosa. On the other hand, the stomach of rats from SGU group (fig. 4B) showed the comparatively extensive damage of the gastric mucosa, and necrotic lesions penetrated deeply into the mucosa. Furthermore, extensive edema and leukocyte infiltrations of the submucosal layer appeared microscopically with severe disruption 
to the surface epithelium. In the pre-treatment groups (VVE, RAN, VVE+RAN), stomach histology showed mild disruption to the surface epithelium and edema of the submucosal layer with leucocyte infiltration and reduced amounts of erosive lesions in the gastric mucosa (Figs. 4C-E). Again, there is a lower power in Crypt abscessing present in both of VVE and VVE+RAN, and hemorrhages in submucosa also observed in VVE. In the post-treatment groups, the gastric mucosal tissues showed almost normal. Post-treatment with VVE shows very mild disruption of the surface epithelium, congestion in blood vessels in RAN treatment was observed. Furthermore, mild edema leukocyte infiltrations were also observed in VVE, RAN and VVE+RAN (fig. 4F-H).

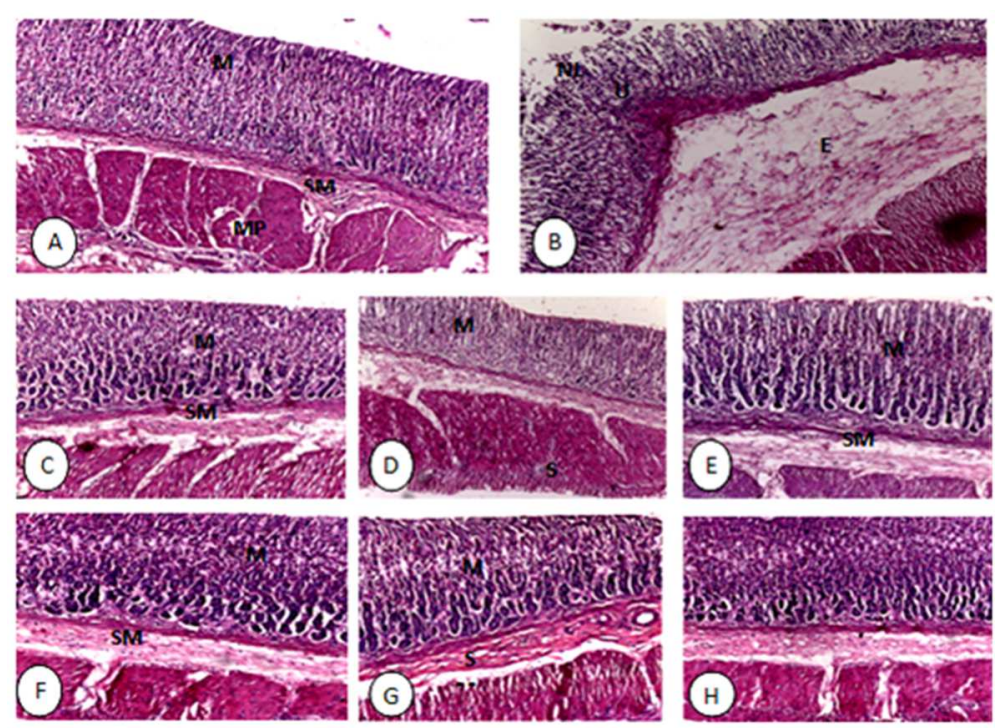

Fig. 4: Histological analysis of gastric mucosa of control and experimental animals ( $\mathrm{H}$ and $\mathrm{E}$ staining $100 \mathrm{x}$ ).

(A) Control gastric mucosa shows the normal architecture of epithelial lining (Mucosa (M), submucosa (SM), muscularies propria (MP)). (B) Gastric mucosa of sever gastric ulcer group shows marked inflammation, neutrophil infiltration and mucosal ulceration with submucosal edema (E). Also, gastric mucosa (M) shows a necrotic lesion (NL) and ulcer (U). (C) Gastric mucosa of VVE pre-treated rats show no ulcers, mucosal regeneration with mild inflammatory cells, and mild edema.(D) Gastric mucosa of RAN pre-treated rats shows mild disruption to the surface epithelium and edema of the submucosa layer with serosal (S) in submucous layers. (E) Gastric mucosa of VVE+RAN pre-treated rats shows mild disruption to the

surface epithelium with edema and leucocyte infiltration of the submucosa layer. (F) Gastric mucosa of VVE post-treated rats shows very mild disruption to the surface epithelium with edema and leucocyte infiltration of the submucosal layer to a mild-moderate condition. (G) Gastric mucosa of RAN post-treated rats shows normal gastric epithelial lining similar to that of control. (H) Gastric mucosa of VVE+RAN post-treated rats shows normal gastric epithelial lining similar to that of control

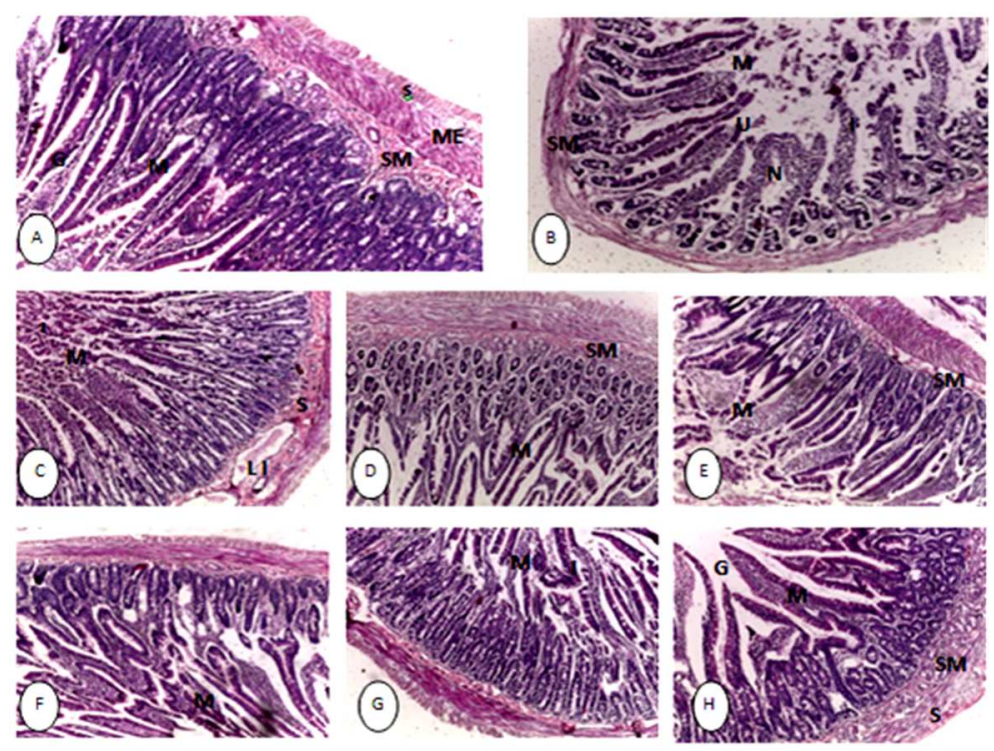

Fig. 5: Histological analysis of duodenal mucosa of control and experimental animals ( $\mathrm{H}$ and $\mathrm{E}$ staining $100 \mathrm{x}$ ).

(A) Control gastric mucosa shows the normal architecture of epithelial lining (Mucosa (M), submucosa (SM), muscular external (ME). (B) The duodenal mucosa of sever gastric ulcer rats shows mucosal necrosis (N), ulcer (U) and hemorrhage in the mucosa. (C) The duodenal mucosa of VVE pre-treated rats shows, hemorrhage in mucosa and leukocyte infiltration (LI) in submucosa layer. (D) Duodenal mucosa of RAN pre-treated rats shows crypt proliferation and hemorrhage in submucosa layer. (E) Duodenal mucosa of VVE+RAN pre-treated rats shows inflammatory infiltrate in lamina propria with an increase in the number of goblet cells (G). (F) Duodenal mucosa of VVE post-treated rats shows little hemorrhage in mucosa as well as normal serosa musculosa, submucosa, and mucosa. (G) The duodenal mucosa of RAN post-treated rats shows normal duodenal epithelial lining similar to that of control. $(\mathrm{H})$ The duodenal mucosa of VVE+RAN post-treated rats shows normal gastric epithelial lining with a large number of goblet cells. 
Duodenum section of rats from the control group revealed the normal structure of both the villi and glands. There are three major layers, mucosa, submucosa and muscularis propria, which were easily identified (fig. 5A). In comparison with control, SGU showed severe infiltration of inflammatory cells in the lamina propria of the mucosal layer; this was accompanied by ulceration of the lining epithelial layer of the mucosa with mucosal necrosis and hemorrhage (fig. 5B). In pre-treated groups (VVE, RAN and VVE+RAN), the duodenal sections revealed moderate improvement, but could not completely restore their normal histological architecture. Pre-treatment with VVE caused a decrease in infiltration of inflammatory cell in the lamina propria, associated with little hemorrhage in submucosa and muscularis mucosa (fig. 5C). In pretreatment groups with RAN and VVE+RAN (fig. 5DandE), crypt proliferation was observed, with some of the inflammatory cell infiltration in VVE+RAN pretreatment group (fig. 5E).

In contrast, the post-treated rats have great improvement in their duodenal histological architecture; duodenum sections showed more compact mucosa in VVE, RAN and VVE+RAN with mild inflammatory cell infiltration in mucosal epithelial after treatment with VVE (fig. 5F) and RAN (fig. 5G). However, VVE+RAN sections showed nearly normal mucosa and submucosa (fig. $5 \mathrm{H}$ ).

\section{DISCUSSION}

The imbalance between gastroduodenal mucosal defenses and counteract aggressive forces are supposed to play an important role in the causation of peptic ulcer [52,53]. Several models mimicking gastroduodenal ulcer have been developed and among these models, administration of indomethacin coupled with hypothermic and restraint stress (SGU) which acquired widespread use and is considered by some experts as the gold standard gastroduodenal ulcer animal models [54, 15]. For the therapeutic strategies of gastroduodenal ulcer disease, it is important to find antioxidant compounds that are able to inhibit the gastric acid secretion, boost the mucosal defense mechanisms by increasing mucosal production, and stabilizing the surface epithelial cells [55]. Natural products were considered as a rich source of compounds for drug discovery [56]. Therefore, by scavenging free radicals, antioxidants from plant sources may play an important role in gastric ulcer therapy. So, the present study aimed to investigate the antiulcerogenic effect of Vitis vinifera extract (VVE) and/or ranitidine (RAN).

1; 1-Diphenyl-2-picrylhydrazyl (DPPH) assays usually used to estimate the antioxidant competence of a compound [57]. The present study showed that the VVE exhibited radical scavenging activity which indicates that it could be a potentially rich source of natural antioxidants. This high antioxidant potential demonstrated by the VVE may be explained by the different chemical components of the crude extract, like flavonoids, tannins, phenolic compounds (saponins and terpenoids) and protein. During the selection of natural supplements for use in healthcare systems, Safety is considered the overriding criterion. Thereby, the present study investigated the acute toxicity study of VVE based on OECD (420) guidelines and showed its safety. $\mathrm{LD}_{50}$ value was found to be greater than $5000 \mathrm{mg} / \mathrm{kg}$ body weight. Thus, the present work suggested that oral administration of $10 \%$ of the limit dose $(500 \mathrm{mg} / \mathrm{kg})$ of VVE does not cause any apparent acute toxicity.

Gastric acid oversecretion is one of the key pathogenic factors for gastric ulcer induction [15]. In the present study, SGU caused a remarkably significant increase in gastric juice discharge, total acidity, and marked peptic ulcer lesions. In consonance with the report of [58], gastric ulcer lesion recorded in the present study may be due to inhibition of prostaglandin synthesis that induced gastric acidity and consequently stomach susceptibility to mucosal injury. Therapeutic agents of peptic ulcers generally depend on the inhibition of gastric acid secretion by histamine $\mathrm{H}_{2}$-antagonists [59, 60]. Pre or post-administration of VVE and/or RAN in the present study induced a significant reduction in volume and acidity of gastric juice as well as an ulcer index. It was reported that Gallic acid in VVE encompasses the ability to prevent and heal gastric mucosal damage induced by NSAIDs by its antihistaminic activity, as well as inhibiting up-regulation of pro-inflammatory cytokines and modulating inflammatory reactions $[61,62]$.
Peptic ulcers are a complex process which includes reactive oxygen species (ROS) generation and extracellular matrix degradation [63, 15]. It was reported that the oxidative stress in gastric tissue causes damage to key biomolecules such as lipids. In conjunction with the report of [64-66], the present study recorded elevations in the levels of the end products of lipid peroxidation, malondialdehyde (MDA) in the gastric tissues following SGU. The elevation in MDA suggests enhanced lipid peroxidation leading to tissue damage and failure of antioxidant defense mechanisms to prevent the formation of excessive free radicals. The underlying mechanisms of increased systemic oxidative stress during gastric mucosal lesions may be due to the generation of oxygen free radicals and lipid peroxidation [67, 65]. However, the decrease of lipid peroxidation mediated oxidative stress may be a potential and effective strategy for the prevention and treatment of peptic ulcer [15]. The present study affirmed the finding of $[68,69]$, who reported that VVE and/or RAN significantly decreased MDA levels in injured gastric and duodenal ulcer due to its antioxidant mechanism, which manifested by the presence of different phytochemical antioxidant components.

Glutathione reduced (GSH) is the major endogenous antioxidant, which counterbalances free radical mediated damage [70]. In accordance with the reports of $[63,65]$, the present study supports the notion that depletion of gastric and duodenal GSH after SGU is one of the major factors that permit lipid peroxidation and subsequent tissue damage. The increase in MDA levels and the concomitant decreased in GSH levels demonstrate the role of oxidative mechanism in sepsis-induced tissue damage [63]. The significant increase in gastric and duodenal GSH levels showed the prophylactic and curative efficacy of VVE and/or RAN treatment in the present work. The increased levels of GSH before or after VVE treatment may be attributed to an increased rate of GSH synthesis or due to increased gastric and duodenal tissue uptake of extracellular GSH. [71] Reported that GSH has been mobilized from blood and other tissues to protect target organs in conditions associated with increased oxidative stress.

The antioxidant enzymes, catalase (CAT), glutathione-S-transferase (GST) and superoxide dismutase (SOD) have been proposed as the key component of a cellular defense system against reactive oxygen species [72] and major biomarkers of gastric oxidative stress [73]. These antioxidant enzymes are natural protective barriers against lipid peroxidation that prevent the generation of hydroxyl radicals and protect the cellular constituents from oxidative damage [74]. Glutathione-S-transferase (GST) is an important enzyme involved in conjugation reaction catalyzing the detoxification of a variety of endogenous and exogenous compounds [75]. Catalase is a highly reactive enzyme that reacts with $\mathrm{H}_{2} \mathrm{O}_{2}$ to form water and molecular oxygen [76-78]. SOD plays an important role in preventing gastric ulcer by catalyzing the breakdown of highly reactive radical superoxide $\left(0^{2-}\right)$ into oxygen and hydrogen peroxide $[79,80]$. In agreement with the report of $[81,15]$ the inhibition of the antioxidant enzymes, SOD and GST following SGU in the present study may be due to the enhancement of the lipid peroxidation which, inhibit protein synthesis and consequently the activities of certain enzymes. In contrary, IND and cold stress induced a significant increase in the CAT activity in the gastric and duodenal tissues. This increase would be due to enhanced oxygen free radical production, which could stimulate antioxidant activities [82] to cope with increased oxidative stress and protect the cells, from damage. Treatment with VVE and/or RAN normalized the antioxidant levels through their rich of flavonoids, tannins, phenolic compounds that have the ability to scavenge free radicals $[68,83]$.

Nitric oxide (NO) is an endogenous defensive factor for gastric cells and exhibits gastroprotective properties against different types of aggressive agents [84]. In the present study, SGU significantly reduced gastric mucosal NO level compared to the control group and enhances mucosal injury [85]. This is attributed to the ability of indomethacin to up regulate the endothelin-1 leading to decrease the production of gastric mucosal NO [86]. Pre or post-treatment with VVE and/or RAN significantly increased mucosal NO level when compared to SGU group [87]. The increment of NO may be due the gastroprotective properties of the VVE that enhanced antioxidant defense system which is known to be embodiments of scavengers 
which mop up free radicals predispose the stomach to inflammation $[30,31]$.

Histological observations of gastric mucosa suggest that SGU induced gastric ulceration that characterized by edema, leukocytes infiltrations, acute necrotic lesion, and hemorrhage. In addition, ulceration and inflammatory infiltration in the duodenal wall were also observed. These findings are in agreement with [88] and [89]. It was reported that gastric lesions induced by indomethacin are characterized by significant oxidative injury and reduced mucosal blood flow mainly due to inhibition of PGs secretion [90]. Oral administration of VVE and/or RAN leading to improvement of gastric and duodenal injuries and decrease the necrotic lesion which may be due to the presence of flavonoids that have been shown to possess high antiulcer activity [91]. The present study confirmed the findings of $[92,31]$ who suggested that healing properties of VVE are attributed to the presence of Gallic acid, polyphenol and flavonoids that have antiulcer activity.

\section{CONCLUSION}

Based on the present study, it was concluded that VVE may have both protective and therapeutic effects of gastric and duodenal ulcers. Therefore, the current study suggested that VVE plays a role in ameliorating the serious effects of SGU model by decreasing MDA and increasing the GSH level as well as improving cellular antioxidant status. In addition, VVE caused improvement of gastric and duodenal lesions. Moreover, healing properties of VVE are attributed to the presence of Gallic acid, polyphenol and flavonoids that have antiulcer activity. However, further studies are necessary to elucidate the mechanisms of their action to ensure the safety of such therapeutic approach.

\section{CONFLICTS OF INTERESTS}

Declared none

\section{REFERENCES}

1. Baracat F, Moura E, Bernardo W, Pu LZ, Mendonça E, Moura D, et al. Endoscopic hemostasis for peptic ulcer bleeding: systematic review and meta-analyses of randomized controlled trials. Surgical Endoscopy 2016;30:2155-68.

2. Laine L, Takeuchi K, Tarnawski A. Gastric mucosal defense and cytoprotection: bench to bedside. Gastroenterology 2008; 135:41-60.

3. Ateufack G, Mokam ECD, Mbiantcha M, Feudjio RBD, David N, Kamanyi A. Gastroprotective and ulcer healing effects of piptadeniastrum Africanum on experimentally induced gastric ulcers in rats. BMC Complementary Altern Med 2015;15:214.

4. Tarnawski A, Ahluwalia A, Jones MK. Gastric cytoprotection beyond prostaglandins: cellular and molecular mechanisms of gastroprotective and ulcer healing actions of antacids. Curr Pharm Des 2013;19:126-32.

5. Hung CR. Importance of histamine, glutathione and oxyradicals in modulating gastric haemorrhagic ulcer in septic rats. Clin Exp Pharmacol Physiol 2000;27:306-12.

6. Salena BJ, Hunt RH. L'estomacet le duodénum, in Principes fond amentaux degastroentérologie: étatspathologiques et démarchesthérapeutiques. 5 ème Ed. Janssen-ortho; 2005. p. 158-98.

7. Ray-Yee Yap P, Goh KL. Non-steroidal anti-inflammatory drugs (NSAIDs) induced Dyspepsia. Curr Pharm Des 2015;21:5073-81.

8. Musumba C, Pritchard DM, Pirmohamed M. Cellular and molecular mechanisms of NSAID-induced peptic ulcer. Rev Aliment Pharmacol Ther 2009;30:517-31.

9. Penney AG, Andrews FJ, O'Brien PE. Effects of misoprostol on delayed ulcer healing induced by aspirin. Dig Dis Sci 1994;39:934-9.

10. Sathyanesan M, Girgenti MJ, Warner-Schmidt J, Newton SS. Indomethacin-induced gene regulation in the rat hippocampus. Mol Brain 2015;8:59.

11. Wallace JL. Mechanisms of protection and healing: current knowledge and future research. Am J Med 2001;110 Suppl 1:S19-23.

12. Takeuchi K, Miyazawa T, Tanaka A, Kato S, Kunikata T. Pathogenic importance of intestinal hypermotility in NSAIDinduced small intestinal damage in rats. Digest 2002;66:30-41.
13. Okayama T, Yoshida N, Uchiyama K, Takagi T, Ichikawa H, Yoshikawa T. Mast cells are involved in the pathogenesis of indomethacin-induced rat enteritis. J Gastroenterol 2009;44:35-9.

14. Dharmani P, Kuchibhotla VK, Maurya R, Srivastava S, Sharma S, Palit G. Evaluation of anti-ulcerogenic and ulcer-healing properties of Ocimum sanctum Linn. J Ethnopharmacol 2004;93:197-206.

15. Fahmy SR, Amer MA, Al-killidar MH. Ameliorative effect of the sea cucumber Holothuriaarenicola extracts against gastric ulcer in rats. J Basic Appl Zool 2015;72:16-25.

16. Chandra K, Salman AS, Mohd A, Sweety R, Ali KN. Protection against FCA induced oxidative stress-induced DNA damage as a model of arthritis and in vitro anti-arthritic potential of costus specious rhizome extract. J Pharm Phytochem Res 2015;7:383-9.

17. Uduak EU, Timbuak JA, Musa SA, Ikyembe DT, Abdurrashid S, Hamman WO. Ulceroprotective effect of methanol extract of Psidium guajava leaves on an ethanol-induced gastric ulcer in adult wistar rats. Asian J Med Sci 2012;4:75-8.

18. Shanthi A, Radha R, Jaysree N. Anti-ulcer activity of newly formulated herbal capsule. Asian J Pharm Clin Res 2011;4:86-9.

19. Al Mofleh IA, Alhaider AA, Mossa JS, Al-Sohaibani MO, Al-Yahya MA, Rafatullah S, et al. Gastroprotective effect of an aqueous suspension of black cumin Nigella sativa on necrotizing agentsinduced gastric injury in experimental animals. Saudi J Gastroenterol 2008;14:128-34.

20. Bourdet DL, Pritchard JB, Thakker DR. Differential substrate and inhibitory activities of ranitidine and famotidine toward human organic cation transporter 1 (hOCT1;SLC22A1), hOCTt2 (SLC22A2), and hOCT3 (SLC22A3). J Pharmacol Exp Ther 2005;315:1288-97.

21. Banji D, Singh J, Banji OJ. Scrutinizing the aqueous extract of leaves of pedalium murex for the antiulcer activity in rats. Pak J Pharm Sci 2010;23:295-9.

22. Alkofahi A, Atta AH. Pharmacological screening of the antiulcerogenic effects of some Jordanian medicinal plants in rats. J Ethnopharmacol 1999;67:341-5.

23. Schmeda Hirschmann G, Yesilada E. Traditional medicine and gastroprotective crude drugs. J Ethnopharmacol 2005;100:61-6.

24. Jayaprakasha GK, Selvi T, Sakariah KK. Antibacterial and antioxidant activities of grape (Vitisvinifera) seed extracts. Food Res Int 2003;36:117-22.

25. Orallo F. Trans-resveratrol: a magical elixir of eternal youth? Curr Med Chem 2008;15:1887-98.

26. Asl MN, Hosseinzadeh H. Review of the pharmacological effects of Vitis vinifera (grape) and its bioactive compounds. Phytother Res 2009;23:1197-204.

27. Ali K, Maltese F, Choi YH, Verpoorte R. Metabolic constituents of grapevine and grape-derived products. Phytochem Rev 2010;9:357-78.

28. Tsao R. Chemistry and biochemistry of dietary polyphenols. Nutrition 2010;2:1231-46.

29. Pastrana-Bonilla E, Akoh CC, Sellappan S, Krewer G. Phenolic content and antioxidant capacity of muscadine grapes. J Agric Food Chem 2003;51:5497-503.

30. Seo DJ, Lee HB, Kim IS, Kim KY, Park RD, Jung WJ. Antifungal activity of gallic acid purified from Terminalia Nigro venulose bark against Fusarium solani. Microb Pathog 2013;56:8-15.

31. Rather SA, Sarumathi A, Anbu S, Saravanan N. Gallic acid protects against immobilization stress-induced changes in wistar rats. J Stress Physiol Biochem 2013;9:136-47.

32. Brand-Williams W, Cuvelier ME, Berset C. Use of a free radical method to evaluate antioxidant activity. LWT-Food Sci Technol 1995;28:25-30.

33. Trease GE, Evans WC. Pharmacognosy. 15th Ed. London: Saunders Publishers; 2002.

34. Parekh J, Chanda S. In vitro screening of antibacterial activity of aqueous and alcoholic extracts of various Indian plant species against selected pathogens from Enterobacteriaceae. Afr J Microbiol Res 2007;1:92-9.

35. Ayoola GA, Ipav SS, Sofidiya MO, Adepoju-Bello AA, Coker HA, Odugbemi TO. Phytochemical screening and free radical scavenging activities of the fruits and leaves of Allanblackia floribunda Oliv (Guttiferae). Int J Health Res 2008;1:87-93. 
36. Kodangala C, Saha S, Kodangala P. Phytochemical studies of aerial parts of the plant Leucaslavandulaefolia. Scholars Res Library Der Pharm Chem 2010;2:434-7.

37. Vanden Heuvel MJ, Clark DG, Fielder RJ, Koundakjian PP, Oliver GJA, Pelling D, et al. The international validation of a fixed-dose procedure as an alternative to the classical LD50 test. Food Chem Toxicol 1999;28:469-82.

38. Whitehead A, Curnow RN. Statistica evaluation of the fixed dose procedure. Food Chem Toxicol 1992;30:313-24.

39. Arai I, Hirose H, Usuki C, Muramatsu M, Aihara H. Effects of indomethacin and cold stress on gastric acid secreation and ulceration. The effect of anti acid secretory agents in rats. Res Commun Chem Pathol Pharmacol 1987;57:313-27.

40. Thong-Ngam D, Choochuai S, Patumraj S, Chayanupatkul M, Klaikeaw N. Curcumin prevents indomethacininduced gastropathy in rats. World J Gastroenterol 2010;18: 1479-84.

41. Jeong Hwan K, Kim B, Kwon H, Nam S. Curative effect of selenium against indomethacin-induced gastric ulcers in rats. J Microbiol Biotechnol 2011;21:400-4.

42. Nguelefack TB, Feumebo CB, Ateufack G, Watcho P, Tatsimo S, Atsamo $\mathrm{AD}$, et al. Antiulcerogenic properties of the aqueous and methanol extracts of leaves of Solanum torvum Swartz (Solanaceae) in rats. J Ethnopharmacol 2008;119:135-40.

43. Parmar NS, Desai JK. A review of the current methodology for the evaluation of gastric and duodenal anti-ulcer agents. Indian J Pharmacol 1993;25:120-35.

44. Kulkarni SK. Handbook of experimental pharmacology. $3^{\text {rd }}$ ed. New Delhi: Vallabh; 2010.

45. Dashputre NL, Naikwade NS. Evaluation of the anti-ulcer activity of methanolic extract of Abutilon indicum Linn leaves in experimental rats. Int J Pharm Sci Drug Res 2011;3:97-100.

46. Ohkawa $\mathrm{H}$, Ohishi N, Yagi K. Assay for lipid peroxides in animal tissues by thiobarbituric acid reaction. Anal Biochem 1979;95:351-8.

47. Aykac J, Uysal M, Yalcin A, Kocak Toke N, Sivas A, Oz H. The effect of chronic ethanol ingestion on hepatic lipid peroxide, glutathione peroxidase and glutathione transferase in rats. Toxicology 1985;36:71-6.

48. Montgomery HAC, Dymock JF. Colorimetric determination of nitrite. Analyst 1961;86:414-6.

49. Aebi H. Catalase in vitro. Methods Enzymol 1948;105:121-6.

50. Habig W, Pabst M, Jakpby W. Glutathione s-transferases the first enzymatic step in mercapturic acid formation. J Biol Chem 1974;249:7130-9.

51. Nishikimi M, Roa NA, Yogi K. The occurrence of the superoxide anion in the reaction of reduced phenazine methosulfate and molecular oxygen. Biochem Biophys Res Commun 1972;46:849-85.

52. Ozbayer C, Kurt H, Ozdemir Z, Tuncel T, Moheb Saadat S, Burukoglu D, et al. Gastroprotective, cytoprotective and antioxidant effects of Oleum cinnamomi on ethanol-induced damage. Cytotechnology 2014;66:431-41.

53. Choudhary M, Kumar V, Singh S. Gastric antisecretory and cytoprotective effects of hydroalcoholic extracts of PlumeriaalbaLinn. Leaves in rats. J Integr Med 2014;12:42-51.

54. Kim JH, Chol SK, Lim WJ, Chang HI. Protective effect of astaxanthin produced by Xantho-phyllomycesden dro rho us mutant on indomethacin-induced gastric mucosal injury in rats. J Microbiol Biotechnol 2004;14:996-1003.

55. Tiwari DK, Tripathi RK, Jena J. Evaluation of antiulcer and antianxiety activity of Aphanamixispolystachya stems bark extract on rats. Int J Pharm Pharm Sci 2013;5:148-51.

56. Harvey AL, Edrada-Ebel R, Quinn RJ. The re-emergence of natural products for drug discovery in the genomics era. Nat Rev Drug Discovery 2015;14:111-29.

57. Kumarasamy Y, Byres M, Cox PJ, Jaspars M, Nahar L, Sarker SD. Screening seeds of some scottish plants for free-radical scavenging activity. Phytotherapy Res 2007;21:615-21.

58. Nagar H, Tiwari P, Jain DK, Chandel HS. Evaluation of the antiulcer activity of stem bark extract of Aphanmixis polystachya in experimental rats. Indian J Pharm Educ Res 2012;46:222-7.

59. Bighetti AE, Antonio MA, Kohn LK, Rehder VLG, Foglio MA, Possenti $\mathrm{A}$, et al. the Antiulcerogenic activity of a crude hydroalcoholic extract and coumarin isolated from mikanialaevigata schultz bip. Phytomedicine 2005;12:72-7.

60. John-Africa BL, Idris-Usman MS, Adzu B, Gamaniel KS. Protective effects of the aqueous extract of Nymphaea lotus L. (Nymphaeaceae) against ethanol-induced gastric ulcers. Int J Biol Chem Sci 2012;6:1917-25.

61. Bhattacharya S, Chatterjee S, Bauri A, Bandivdeker $\mathrm{AH}$, Chattopadhyay S, Bandyopadhyay SK, et al. Immunopharmacological basis of the healing of indomethacininduced gastric mucosal damage in rats by the constituents of phyllanthusemblica. Curr Sci 2007;93:47-55.

62. Pal C, Bindu S, Dey S, Alam A, Goyal M, Iqbal MS, et al. Gallic acid prevents nonsteroidal anti-inflammatory drug-induced gastropathy in the rat by blocking oxidative stress and apoptosis. Free Radicals Biol Med 2010;49:258-67.

63. Mei XT, Xu DH, Xu SK, Zheng YP, Xu SB. Zinc(II)-curcumin accelerates the healing of acetic acid-induced chronic gastric ulcers in rats by decreasing oxidative stress and downregulation of matrix metalloproteinase-9. Food Chem Toxicol 2013;60:448-54.

64. Ajeigbe K, Oladejo E, Emikpe B, Asuk A, Olaleye S. The dual modulatory effect of folic acid supplementation on indomethacin-induced gastropathy in the rat. Turk J Gastroenterol 2012;23:639-45.

65. Abbas Am, Sakr HF. Effect of selenium and grape seed extract on indomethacin-induced gastric ulcers in rats. J Physiol Biochem 2013;69:527-73.

66. Pérez Y, Oyárzabal A, Mas R, Molina V, Jiménez S. Protective effect of D-002, a mixture of beeswax alcohols, against indomethacin-induced gastric ulcers and mechanism of action. J Nat Med 2013;67:182-9.

67. Vemula SK, Chawada MB, Thakur KS, Vahalia MK. Antiulcer activity of Amlapitta mishran suspension in rats: a pilot study. Ancient Sci Life 2012;32:112-5.

68. Şendoğdu N, Aslan M, Orhand D, Ergun F, Yesllada E. Antidiabetic and antioxidant effects of Vitis vinifera L. leaves in streptozotocin-diabetic rats. Turkish J Pharm Sci 2006;3:7-18.

69. de Lira Mota KS, Dias GEN, Pinto MEF, Luiz-Ferreira Â, Monteiro Souza-Brito AR, Hiruma-Lima CA, et al. Flavonoids with gastroprotective activity. Molecules 2009;14:979-1012.

70. Pushpakiran G, Mahalakshmi K, Anuradha CV. Protective effects of taurine on glutathione and glutathione-dependent enzymes in ethanol-fed rats. Pharmazie 2004;59:869-72.

71. Lii CK, Ko YJ, Chiang MT, Sung WC, Chen HW. Effect of dietary vitamin $\mathrm{E}$ on antioxidant status and antioxidant enzyme activities in sprague-dawley rats. Nutr Cancer 1992;32:95-100.

72. Nartey ET, Ofosuhene, Agbale cM. The anti-ulcerogenic activity of the root bark extract of the African laburnum" cassia sieberiana" and its effect on the antioxidant defense system in rats. BMC Complementary Altern Med 2012;10:247.

73. Radovanović TB, Borković-Mitić SS, Perendija BR, Despotović SG, Pavlović SZ, Cakić PD, et al. Superoxide dismutase and catalase activities in the liver and muscle of barbel (Barbusbarbus) and its intestinal parasite (Pomphoryinchuslaevis) from the danube river, Serbia. Arch Biol Sci 2010;62:97-105.

74. Halliwell B, Gutteridge JM. Oxygen toxicity, oxygen radicals, transition metals and disease. Biochem J 1984;219:1-14.

75. Khan MS, Khan MK, Siddiqui MH, Arif JM. An in vivo and in silico approach to elucidate the tocotrienol-mediated fortification against infection and inflammation induced alterations in antioxidant defense system. Eur Rev Med Pharmacol Sci 2011;15:916-30.

76. Halici M, Odabasoglu F, Suleyman H, Cakir A, Aslan A, Bayir Y. Effect's of water extract of Usnealongissima on antioxidant enzyme activity and mucosal damage caused by indomethacin in rats. Phytomedicine 2005;12:656-62.

77. Bayir Y, Odabasoglu F, Cakir A, Aslan A, Suleyman H, Halici M, et al. The inhibition of gastric mucosal lesion, oxidative stress and neutrophil infiltration in rats by the lichen constituent diffractaic acid. Phytomedicine 2006;13:584-90.

78. Odabasoglu F, Cakir A, Suleyman H, Aslan A, Bayir Y, Halici M, et al. Gastroprotective and antioxidant effects of usnic acid on indomethacin-induced gastric ulcer in rats. J Ethnopharmacol 2006;103:59-65. 
79. Zelko IN, Mariani TJ, Folz RJ. Superoxide dismutase multigene family: a comparison of the CuZn-SOD (SOD1), Mn-SOD (SOD2), and EC-SOD (SOD3) gene structures, evolution, and expression. Free Radical Biol Med 2002;33:337-49.

80. Heeba GH, Hassan MK, Amin RS. Gastroprotective effect of simvastatin against indomethacin-induced gastric ulcer in rats: the role of nitric oxide and prostaglandins. Eur J Pharmacol 2009;607:188-93.

81. Badr GM, AL-Mulhim JA. The protective effect of aged garlic extract on nonsteroidal anti-inflammatory drug-induced gastric inflammations in male albino rats. J Evidence Based Complementary Altern Med 2014. Doi:10.1155/2014/759642.

82. Torres MA, Testa CP, Gaspari C, Masutti MB, Panitz CMN, CuriPedrosa $\mathrm{R}$, et al. Oxidative stress in the mussel Mytellaguyanensis from polluted mangroves on Santa Catarina Island, Brazil. Mar Pollut Bull 2002;44:923-32.

83. Fernandes F, Ramalhosa E, Pires P, Verdial J, Valentão P, Andrade $\mathrm{P}$, et al. Vitis vinifera leaves towards bioactivity. Ind Crops Prod 2013;43:434-40.

84. Samini M, Moezi L, Jabarizadeh N, Tavakolifar B, Shafaroodi H, Dehpour AR. Evidence for the involvement of nitric oxide in the gastroprotective effect of bromocriptine and cyclosporin A on water immersion stress-induced gastric lesions. Pharm Res 2002;46:519-23.

85. Holzer P. Neural regulation of gastrointestinal blood flow. In: Physiology of the gastrointestinal tract. LR Johnson. 4th Ed. Academic Press: New York, EUA; 2006. p. 817-39.

86. Slomiany BL, Slomiany A. Role of endothelin converting enzyme-1 in the suppression of constitutive nitric oxide synthase in rat gastric mucosal injury by indomethacin. Scand J Gastroenterol 2000;35:1131-6.

87. Matsuda H, Morikawa T, Ando S, Toguchida I, Yoshikawa M. Structural requirements of flavonoids for nitric oxide production inhibitory activity and mechanism of action. Bioorg Med Chem 2003;11:1995-2000.

88. Elegbe RA. Comparative studies on starvation and indomethacin-induced ulceration in albino rats. Biochem Exp Biol 1978;14:158-66.

89. Olaleye SB, Ajeigbe KO. Attenuation of experimental gasric ulceration by sulfadoxine-pyrimethamine in albino Rats. J Med Sci 2009;9:87-92.

90. Robert A, Nezamis JE, Lancaster C, Hanchar AJ. Cytoprotection by prostaglandins in rats. Prevention of gastric necrosis produced by alcohol, $\mathrm{HCl}, \mathrm{NaOH}$, hypertonic $\mathrm{NaCl}$, and thermal injury. Gastroenterol 1979;77:433-43.

91. Olaleye SB, Farombi EO. Attenuation of Indomethacin and $\mathrm{HCl} /$ Ethanol-induced oxidative gastric mucosa damage in rats by kolaviron (Garcinia bi flavanones). Phytother Res 2006;20:14-20.

92. Devi SA, Chandrasekar BS, Manjula KR, Ishii N. Grape seed proanthocyanidin lowers brain oxidative stress in adult and middle-aged rats. Exp Gerontol 2011;46:958-64.

\section{How to cite this article}

- Dawlat A Sayed, Sohair R Fahmy, Amel M Soliman, Nagat S Hussein. Antiulcerogenic efficacy of an ethanolic extract of vitis vinifera leaves in rats. Int J Pharm Pharm Sci 2016;8(9):163-172. 